\title{
Rapid and sensitive enumeration of total coliforms and Escherichia coli in water and foods by most-probable-number loop-mediated isothermal amplification (MPN-LAMP) method
}

\author{
Chonnikan Tongphrom ${ }^{\mathrm{a}}$, Sutima Preeprem ${ }^{\mathrm{a}}$, Mitsuaki Nishibushi ${ }^{\mathrm{b}}$, Varaporn Vuddhakul ${ }^{\mathrm{a}}$, \\ Pimonsri Mittraparp-arthorn ${ }^{\mathrm{a}, *}$ \\ a Department of Microbiology, Faculty of Science, Prince of Songkla University, Hat Yai, \\ Songkhla 90110 Thailand \\ b Division of Human-Nature Dynamics, Centre for Southeast Asian Studies, Kyoto University, Sakyo-ku, \\ Kyoto 606-8501 Japan
}

*Corresponding author, e-mail: pimonsri.m@psu.ac.th

Received 6 Jul 2018

Accepted 1 Oct 2018

\begin{abstract}
Total coliforms and Escherichia coli are bacterial indicators used to assess the microbiological qualities of water and foods. In this study, we developed a most-probable-number loop-mediated isothermal amplification (most probable number (MPN-LAMP)) method for the enumeration of total coliforms and E. coli in drinking water and vegetables. The LAMP primers were designed based on lacZ (lacZ-LAMP) and uidA (uidA-LAMP) genes for the detection of total coliforms and E. coli, respectively. In pure culture, the lacZ-LAMP and the uidA-LAMP were able to detect all of the 37 coliforms and $30 \mathrm{E}$. coli strains, respectively. In the artificially contaminated drinking water and vegetables, the combination of MPN and LAMP techniques (MPN-LAMP) was able to detect $E$. coli at 1 colony-forming unit (CFU) $/ 100 \mathrm{ml}$ and $5 \mathrm{CFU} / \mathrm{g}$, respectively. From analysis of 33 drinking water and 46 vegetable samples, the total coliform detection obtained by the MPN-LAMP method was in agreement with the MPN detection technique. However, MPN-LAMP was more sensitive than the MPN technique for E. coli detection. Our findings revealed that the MPN-LAMP assay was more rapid and highly sensitive than MPN method. Thus this method could be considered for detection and enumeration of total coliforms and $E$. coli in the food industry.
\end{abstract}

KEYWORDS: loop-mediated isothermal amplification, microbial quality

\section{INTRODUCTION}

Coliforms are present predominantly in the faeces of warm-blooded animals, including humans, and are detected in various environments such as water, soil, and vegetation ${ }^{1,2}$. Total coliforms and Escherichia coli are used as the indicator bacteria for the monitoring of the microbial qualities of water and food. It has been demonstrated that the commonest coliforms isolated from rural drinking water are Klebsiella spp., Citrobacter spp., and E. coli, accounting for $51 \%, 20 \%$, and $12 \%$ of the total coliforms, respectively ${ }^{3}$. In several countries, the presence of E.coli is not acceptable in drinking water, fresh produce, and any processed food ${ }^{4,5}$.

A standard method recommended for the detection and enumeration of total coliforms and E. coli is the most probable number (MPN) technique ${ }^{6}$. However, this technique is time consuming, and
4-6 days are required before the presence of coliforms can be confirmed. Rapid culture methods for coliforms based on specific enzymatic activity ( $\beta$-galactosidase and $\beta$-glucuronidase) have been developed to examine water and food samples, but they are expensive and time consuming ${ }^{7}$.

Polymerase chain reaction (PCR)-based methods have been developed to increase the rapidity and specificity of coliform detection ${ }^{8,9}$. Primers specific to $l a c Z$ and $m a l B$ genes have been developed for the detection of coliforms and $E$. coli, respectively; however, cross reaction has been demonstrated with Shigella and Salmonella species ${ }^{10}$. Hence primers targeted to the uidA gene encoding $\beta$-Dglucuronidase (GUD) have been developed for the specific detection of E. coli11,12. However, PCR requires expensive equipment, and the presence of inhibitors in food samples can decrease PCR effi- 
Table 1 Bacteria used in this study and specificity of LAMP primers.

\begin{tabular}{lccc}
\hline Bacteria & $\mathrm{No}^{\dagger}$ & lacZ-LAMP & uidA-LAMP \\
\hline Coliforms $(n=37)$ & & & \\
$\quad$ Escherichia coli & 30 & $+^{\mathrm{a}}$ & + \\
C. freundii & 1 & + & - \\
$\quad$ Enterobacter aerogenes & 1 & + & - \\
Enterobacter cloacae & 1 & + & - \\
K. pneumoniae & 3 & + & - \\
$\quad$ Serratia marcescens & 1 & + & - \\
Non-coliforms $(n=15)$ & & & \\
$\quad$ Proteus spp. & 3 & - & - \\
$\quad$ Salmonella enterica & 4 & - & - \\
Shigella spp. & 4 & + & + \\
Aeromonas spp. & 2 & - & - \\
$\quad$ Plesiomonas shigelloides & 1 & - & - \\
Pseudomonas aeruginosa & 1 & - & - \\
\hline
\end{tabular}

$\dagger$ Number of tested strains.

+ , positive result; - , negative result.

ciency $^{13}$.

A novel nucleic acid-based method known as loop-mediated isothermal amplification (LAMP) has been developed ${ }^{14}$. The LAMP technique is rapid and easy to perform. Bacterial DNA amplification can be achieved under isothermal conditions by using a simple heating block or water bath, and a positive LAMP reaction can be detected by the naked eye ${ }^{15}$. In addition, LAMP showed higher tolerance to some biological substances and to inhibitory substances found in a culture medium and some biological substances than did PCR ${ }^{16}$. LAMP commercial kits have been developed to detect many foodborne pathogens, including Salmonella, Listeria, Shigatoxin-producing E. coli, and Campylobacter ${ }^{15}$. Diagnosis of $E$. coli infection with this technique reveals high sensitivity and specificity ${ }^{13,17}$. For food safety and for microbial detection in food, the concentrations of some bacteria must be inspected and reported as MPN value; however, the LAMP technique is not applicable in this context. Thus combining the MPN and LAMP techniques (MPN-LAMP) would benefit the food industry by allowing the rapid detection and enumeration of foodborne pathogens. MPN-LAMP has been reported as a potential approach to replace conventional MPN method for detection of many foodborne pathogens, including Vibrio parahaemolyticus, E. coli, and Enterococcus faecalis $^{18,19}$. In this work, the MPN-LAMP technique was evaluated for the detection and enumeration of total coliforms and $E$. coli in drinking water and vegetables.
Table 2 LAMP target genes and primers used in this study.

\begin{tabular}{lcl}
\hline Target gene & Primer & Sequence $\left(5^{\prime}\right.$ to $\left.3^{\prime}\right)$ \\
\hline lacZ & F3 & ACCATCGTCTGCTCATCCA \\
& B3 & TTAAACTGCACACCGCCG \\
& FIP & CAAGCCGTTGCTGATTCGCGTTT \\
& TGACCTGACCATGCAGAGG \\
& BIP & CCGTTCAGCAGCAGCAGACCTTTT \\
& & ACGCTGATTGAAGCAGAAGC \\
& F3 & CCAGAGGTGCGGATTCAC \\
& B3 & CGATATCACCGTGGTGACG \\
& FIP & ACTGCGTGATGCGGATCAACAGTT \\
& BTCACTTGCAAAGTCCCGCTAG & CTGACATCACCATTGGCCACCATT \\
& & TTGTCGCGCAAGACTGTAACC \\
\hline
\end{tabular}

\section{MATERIALS AND METHODS}

\section{Bacterial strains}

A total of 52 coliform and non-coliform bacteria used in this study (Table 1) were obtained from the culture collection of the Department of Microbiology, Faculty of Science, Prince of Songkla University, Hat Yai, Songkhla, Thailand.

\section{LAMP assay}

In this study, primers specific to lacZ and uidA for the detection of total coliforms and E. coli, respectively, were designed using Primer Explorer V4 (Eiken Chemical, Co. Ltd., Japan) (Table 2). The lacZLAMP or uidA-LAMP assay was performed in a 25$\mu l$ reaction mixture consisting of a $1 \times$ ThermoPol reaction buffer $(20 \mathrm{mM}$ Tris- $\mathrm{HCl}, 50 \mathrm{mM} \mathrm{KCl}, 10 \mathrm{mM}$ $\left(\mathrm{NH}_{4}\right)_{2} \mathrm{SO}_{4}, 2 \mathrm{mM} \mathrm{MgSO}$, $0.1 \%$ TritonX-20, pH8.8 at $25^{\circ} \mathrm{C}$ ), $1.6 \mu \mathrm{M}$ of each inner primer (FIP and BIP), $0.2 \mu \mathrm{M}$ each of the outer primer (F3 and B3), $1.4 \mathrm{mM}$ of dNTPs, $8 \mathrm{mM}$ of $\mathrm{MgSO}_{4}, 8 \mathrm{U}$ of Bst DNA polymerase (New England Biolabs, USA), and $1.5 \mu \mathrm{l}$ of DNA template. The reaction mixture was incubated in a conventional heating block (Major Science, USA) for $60 \mathrm{~min}$ at $65^{\circ} \mathrm{C}$ for lacZ detection and at $64^{\circ} \mathrm{C}$ for uidA detection. No DNA-containing reaction mixture was used as a negative control. In this work, for rapid visualization of the LAMP reaction, Pico Green (Sigma-Aldrich, USA) was added to the reaction mixture after the amplification, and green fluorescence was detected for a positive LAMP reaction ${ }^{20}$. Separate areas were used for LAMP reaction setup and analysis to prevent carry-over contamination. Conventional PCR was performed using the LAMP outer primers F3 and B3 (Table 2); the amplified products were then purified and sequenced (Macrogen, Korea) to verify the specificity 
of the primers.

\section{Specificity and sensitivity of the LAMP assay}

To determine the specificity of the LAMP assay, 37 and 15 strains of coliforms and non-coliforms were evaluated, respectively (Table 1). The sensitivity of the lacZ-LAMP and the uidA-LAMP were determined using $E$. coli ATCC25922. Briefly, the bacterium was grown overnight at $35^{\circ} \mathrm{C}$ in tryptic soy broth and adjusted to $10^{8} \mathrm{CFU} / \mathrm{ml}$ in normal saline solution using a densitometer (Biosan, Latvia). Then 10fold serial dilution of bacteria was performed and the number of bacteria was confirmed by the spread plate technique ${ }^{24}$. Bacterial DNA template for the LAMP assay was obtained by boiling. For comparison, the conventional PCR was also performed on the serially diluted DNA templates using the LAMP outer primers F3 and B3.

\section{Artificial inoculation of water and a vegetable}

E. coli is a member of the coliform group. In this work, E. coli ATCC25922 was used to determine both total coliform and E. coli contamination in samples. A drinking water sample was obtained from a public water dispenser, and lettuce was purchased from a local market. Natural bacterial contamination in water was removed by filtration through a $0.22 \mu \mathrm{m}$ membrane filter (Sartorius Stedim Biotech, Germany). For artificial c ontamination, $1 \mathrm{ml}$ of E. coli at a concentration of between 1 and $10^{2}$ $\mathrm{CFU} / \mathrm{ml}$ was inoculated into $200 \mathrm{ml}$ of water. For a vegetable sample, $100 \mathrm{~g}$ of lettuce was decontaminated using $200 \mathrm{ppm}$ of sodium hypochlorite ${ }^{21}$. A concentration of E. coli between 1 and $10^{2} \mathrm{CFU} / \mathrm{ml}$ was inoculated into a sample containing $25 \mathrm{~g}$ of vegetable and $225 \mathrm{ml}$ of phosphate buffer, and the sample was homogenized for $2 \mathrm{~min}$.

\section{MPN and the MPN-LAMP assays in artificially contaminated samples}

To enumerate total coliforms and $E$. coli in water, the MPN technique was performed using the 10-tube MPN test with lauryl tryptose broth as described by the U.S. Environmental Protection Agency ${ }^{22}$. For lettuce, the three-tube MPN test was performed as described in the Bacteriological Analytical Manual $(\mathrm{BAM})^{23}$.

For MPN-LAMP evaluation, positive presumptive MPN tubes that exhibited gas formation were subjected to the lacZ-LAMP and the uidA-LAMP for the detection of total coliforms and E. coli, respectively. Briefly, $1 \mathrm{~m} \mathrm{l}$ of $\mathrm{c}$ ulture $\mathrm{t}$ aken $\mathrm{f}$ rom each positive presumptive tube was boiled, and $2 \mu l$ of supernatant was used as a DNA template for each LAMP assay as described above.

\section{MPN-LAMP assay in naturally contaminated water and vegetable samples}

A total of 33 drinking water samples were collected from various public water dispensers in Hat Yai, Songkhla province, southern Thailand. The samples were transported and stored in strict accordance with the guidelines described for standard methods $^{22}$. Forty-six vegetable samples were purchased from local markets and were analysed immediately upon their arrival at the laboratory. For the enumeration of total coliforms and E. coli in water and vegetables, the 10-tube MPN test and the 3-tube MPN test were performed, respectively, and MPN tubes that exhibited gas formation were subjected to the lacZ-LAMP and the uidA-LAMP as described above.

The specificity and sensitivity of MPN and MPNLAMP were evaluated. Specificity was defined as the (number of true negatives)/ (number true negatives + number of false positives), and sensitivity was defined as the (number of true positives)/(number of true positives + number of false negatives) ${ }^{24}$.

\section{RESULTS}

\section{Specificity and sensitivity of the LAMP assay}

Regarding the specificity of the lacZ-LAMP for total coliform detection, all tested coliform bacteria, including E. coli, Citrobacter freundii, Enterobacter aerogenes, Enterobacter cloacae, Klebsiella pneumoniae, and Serratia marcescens, were positive (Table 1). All strains of non-coliform bacteria, including Proteus, Salmonella, and others were negative except for Shigella spp. Regarding the specificity of uidA-LAMP for E. coli detection, all $30 \mathrm{E}$. coli and Shigella spp. strains were positive, whereas other tested bacteria were negative (Table 1). Confirmation of LAMP amplification products by sequencing revealed no false positives detected in both the lacZLAMP and the uidA-LAMP assays. In this study, the sensitivity for $E$. coli by both assays was $1 \mathrm{CFU}$ per reaction, which was 1000 times more sensitive than the sensitivity obtained by conventional PCR (Fig. 1).

\section{MPN-LAMP assays in artificially contaminated samples}

The sensitivities of the MPN and MPN-LAMP techniques to detect total coliforms and $E$. coli were compared. In the artificially contaminated water, 

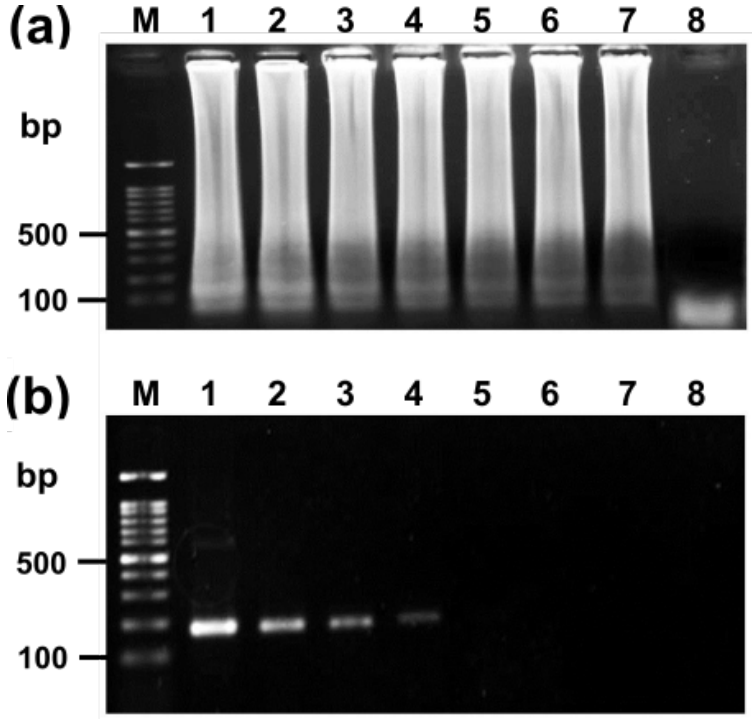

Fig. 1 Sensitivity of LAMP (a) and PCR (b) assays for detection of Escherichia coli. The 10-fold serial dilutions of E. coli ATCC25922 starting from $10^{6} \mathrm{CFU} /$ reaction (lane 1) down to $1 \mathrm{CFU} /$ reaction (lane 7) were tested. Lane 8 , non-template control; lane M, DNA marker.

the MPN-LAMP method was able to detect total coliforms and E. coli at the lowest concentration of $1 \mathrm{CFU} / 100 \mathrm{ml}$, which correlated with the results obtained from the MPN technique. In the artificially contaminated vegetable, the sensitivity of both methods for total coliforms and E. coli was lower (5 CFU/g).

\section{MPN-LAMP assay in naturally contaminated water and vegetable samples}

The efficiency of the MPN-LAMP method was determined in 33 drinking water and 46 vegetable samples to evaluate its application in water and food analysis. For all tested samples, MPN-LAMP was capable of detecting the numbers of total coliforms positive sample equally to the MPN technique. The total coliforms concentrations in water and vegetable samples were between $<1.1$ $10^{2} \mathrm{MPN} / 100 \mathrm{ml}$ and $3.6-4.6 \times 10^{4} \mathrm{MPN} / \mathrm{g}$, respectively (data not shown). However, for the detection of $E$. coli at the same concentrations, the numbers of positive samples obtained by the MPNLAMP assay were different from those of the MPN technique. In this study, a discrepancy between the MPN technique and the MPN-LAMP method for the detection of $E$. coli in 11 samples (14\%) was observed (Table 3).

The sensitivity and specificity of the MPN-LAMP
Table 3 Comparison of MPN and MPN-LAMP techniques for enumeration of total coliforms and Escherichia coli in drinking water and vegetables.

\begin{tabular}{|c|c|c|c|c|}
\hline \multirow{2}{*}{ Sample } & \multicolumn{2}{|c|}{ Total coliforms } & \multicolumn{2}{|r|}{ E. coli } \\
\hline & MPN & MPN-LAMP & MPN & MPN-LAMP \\
\hline water & $1.1^{\mathrm{a}}$ & 1.1 & $<1.1$ & 1.1 \\
\hline water & 1.1 & 1.1 & $<1.1$ & 1.1 \\
\hline water & 2.2 & 2.2 & $<1.1$ & 2.2 \\
\hline water & 2.2 & 2.2 & $<1.1$ & 2.2 \\
\hline water & 9.2 & 9.2 & $<1.1$ & 3.6 \\
\hline water & 16 & 16 & $<1.1$ & 1.1 \\
\hline water & 23 & 23 & $<1.1$ & 9.2 \\
\hline vegetable & 23 & 23 & $<3.0$ & 9.2 \\
\hline vegetable & $>1.1 \times 10^{3}$ & $>1.1 \times 10^{3}$ & $<3.0$ & 35 \\
\hline vegetable & $1.1 \times 10^{4}$ & $1.1 \times 10^{4}$ & $<3.0$ & 3.0 \\
\hline vegetable & $1.5 \times 10^{4}$ & $1.5 \times 10^{4}$ & $<3.0$ & 9.2 \\
\hline
\end{tabular}

method for the detection of total coliforms and E. coli in 79 samples of water and vegetable were compared to the MPN technique. The results obtained from MPN-LAMP correlated to those obtained from MPN for total coliform detection; thus both the specificity and sensitivity of the MPNLAMP technique for coliform detection were 100\% (Table 4). However, for $E$. coli detection, 54 samples were positive by MPN-LAMP, whereas only 43 samples were positive by MPN; thus the sensitivity of MPN-LAMP was superior to MPN for $E$. coli detection (Table 4).

\section{DISCUSSION}

The MPN technique, the conventional culture-based method for the detection and enumeration of total coliforms and E. coli in water and food, is laborious and time consuming. Recently, the LAMP assay, which is 10 times more sensitive than $\mathrm{PCR}^{25}$, has been developed for the detection of many foodborne pathogens. For the examination of the microbiological qualities of drinking water and food, bacterial count must be evaluated to determine whether they are below the permissible limits. MPN is a standard method used to estimate the concentration of viable bacterial cells. However, LAMP technique detects the amounts of DNA in a reaction tube, rather than bacterial cells as requested in food safety standard and guidelines ${ }^{13}$. Hence a combination of this technique and the MPN method has been developed in this study for the detection of bacterial indicators in water and food. 
Table 4 Specificity and sensitivity of MPN technique compared to MPN-LAMP method for total coliforms and Escherichia coli detection.

\begin{tabular}{lccccccc}
\hline \multirow{2}{*}{ Bacteria } & \multicolumn{2}{c}{ MPN } & \multirow{2}{*}{ \% specificity } & \% sensitivity & \multicolumn{2}{c}{ MPN-LAMP } & \multirow{2}{*}{ \% sensitivity } \\
\cline { 2 - 3 } & $+^{\mathrm{a}}$ & - & & & + & - & $100 \%$ \\
\hline Total coliforms & 59 & 20 & $100 \%$ & $100 \%$ & 59 & 20 & $100 \%$ \\
E. coli & 43 & $36^{\mathrm{b}}$ & $100 \%$ & $80 \%$ & 54 & 25 & $10 \%$ \\
\hline
\end{tabular}

${ }^{\mathrm{a}}$ Number of positive samples; ${ }^{\mathrm{b}}$ E. coli was detected from 11 Lauryl tryptose broth MPN tubes by direct cultivation on Eosin Methylene Blue agar and was confirmed by 16S rRNA sequencing.

In this study, the lacZ-LAMP (total coliforms) and the uidA-LAMP (E. coli) assays were found to be highly specific. It has been reported that $E$. coli and Shigella share a high level of DNA similarity and cannot be differentiated by PCR-based methods ${ }^{8}$. In this study, the presence of coliforms and $E$. coli can be confirmed on the basis of the ability to ferment lactose during the MPN step of MPN-LAMP assay, which is not the case for Shigella spp.

Our data demonstrate that the sensitivity of MPN-LAMP for the detection of total coliforms or E. coli was superior to that of the LAMP assay. A previous report demonstrated that the sensitivity of the LAMP assay for Shiga-toxin-producing E. coli (based on Shiga toxin genes, other virulence genes, and O-antigen gene clusters) was between 1 and 20 cells per reaction in pure culture and $10^{3}$ and $10^{4}$ $\mathrm{CFU} / \mathrm{g}$ in vegetables ${ }^{26}$. The sensitivity of LAMP for the detection of enterotoxigenic E. coli in raw milk was $547 \mathrm{CFU} / \mathrm{ml}^{27}$.

Results from the experiments to detect total coliforms and E. coli in drinking water and vegetable samples have shown that MPN-LAMP was more sensitive than the MPN technique for $E$. coli detection. The false-negative results of MPN alone might be due to some strains of $E$. coli being unable to grow in Escherichia coli broth (EC broth) during the confirmed phase of conventional MPN method. When the initial density of $E$. coli was low, the presence of bile salts in the EC medium and incubation at $45.5^{\circ} \mathrm{C}$ were inhibitory to many of the strains tested $^{28}$. However, the MPN-LAMP assay can overcome the problems occurred by MPN method. To confirm this, an MPN tube that exhibited gas formation at presumptive phase was directly streaked on eosin methylene blue agar, and a lactose-fermenting colony was subjected to sequencing based on the $16 S$ rRNA gene, and E. coli was identified. The failure to detect $E$. coli could lead to a significant error in the examination of water and food quality. The uidA-PCR has been demonstrated to be more sensitive for $E$. coli detection than culture-based detection methods ${ }^{9}$. This study also demonstrated that the MPN-LAMP based on uidA for E. coli detection is more sensitive than the conventional MPN technique. Thus the MPN-LAMP assay is effective for application in coliform detection in water and food.

This study demonstrates that the MPN-LAMP method is a rapid and reliable technique for the detection and enumeration of total coliforms in drinking water and vegetables and may be considered as a useful tool for application in the food industry.

Acknowledgements: This work was supported by a research grant from the Thailand Research Fund (grant number TRG5680055). Partial supports from the Faculty of Science Research Fund and Prince of Songkla University are gratefully acknowledged.

\section{REFERENCES}

1. Geldreich EE, Kenner B, Kabler P (1964) Occurrence of coliforms, fecal coliforms, and streptococci on vegetation and insects. Appl Microbiol 12, 63-9.

2. Tate RL (1978) Cultural and environmental factors affecting the longevity of Escherichia coli in histosols. Appl Environ Microbiol 35, 925-9.

3. Ramteke PW, Bhattacharjee JW, Pathak SP, Kalra N (1992) Evaluation of coliforms as indicators of water quality in India. $J$ Appl Bacteriol 72, 352-6.

4. Ng Y-F, Wong S-L, Cheng H-L, Yu PH-F, Chan S-W (2013) The microbiological quality of ready-to-eat food in Siu Mei and Lo Mei shops in Hong Kong. Food Control 34, 547-53.

5. Oliveira MAd, Maciel de Souza V, Morato Bergamini AM, De Martinis ECP (2011) Microbiological quality of ready-to-eat minimally processed vegetables consumed in Brazil. Food Control 22, 1400-3.

6. Eckner KF (1998) Comparison of membrane filtration and multiple-tube fermentation by the Colilert and Enterolert methods for detection of waterborne coliform bacteria, Escherichia coli, and Enterococci used in drinking and bathing water quality monitoring in Southe. Appl Environ Microbiol 64, 3079-83.

7. Maheux AF, Dion-Dupont V, Bouchard S, Bisson MA, Bergeron MG, Rodriguez MJ (2015) Compar- 
ison of four $\beta$-glucuronidase and $\beta$-galactosidasebased commercial culture methods used to detect Escherichia coli and total coliforms in water. $J$ Water Health 13, 340.

8. Bej AK, McCarty SC, Atlas R (1991) Detection of coliform bacteria and Escherichia coli by multiplex polymerase chain reaction: comparison with defined substrate and plating methods for water quality monitoring. Appl Environ Microbiol 57, 2429-32.

9. AK, McCarty SC, Atlas RM (1991) Detection of coliform bacteria and Escherichia coli by multiplex polymerase chain reaction: comparison with defined substrate and plating methods for water quality monitoring. Appl Environ Microbiol 57, 2429-32.

10. Bej AK, Steffan RJ, DiCesare J, Haff L, Atlas RM (1990) Detection of coliform bacteria in water by polymerase chain reaction and gene probes. Appl Environ Microbiol 56, 307-14.

11. Martins MT, Rivera IG, Clark DL, Stewart MH, Wolfe RL, Olson BH (1993) Distribution of uidA gene sequences in Escherichia coli isolates in water sources and comparison with the expression of betaglucuronidase activity in 4-methylumbelliferyl-betaD-glucuronide media. Appl Environ Microbiol 59, 2271-6.

12. Tsai YL, Palmer CJ, Sangermano LR (1993) Detection of Escherichia coli in sewage and sludge by polymerase chain reaction. Appl Environ Microbiol 59, 353-7.

13. Hill J, Beriwal S, Chandra I, Paul VK, Kapil A, Singh T, Wadowsky RM, Singh V, Goyal A, Jahnukainen T, Johnson JR, Tarr PI, Vats A (2008) Loop-mediated isothermal amplification assay for rapid detection of common strains of Escherichia coli. J Clin Microbiol 46, 2800-4.

14. Notomi T, Okayama H, Masubuchi H, Yonekawa T, Watanabe K, Amino N, Hase T (2000) Loop-mediated isothermal amplification of DNA. Nucleic Acids Res 28.

15. Mori Y, Nagamine K, Tomita N, Notomi T (2001) Detection of loop-mediated isothermal amplification reaction by turbidity derived from magnesium pyrophosphate formation. Biochem Biophys Res Commun 289, 150-4.

16. Kaneko H, Kawana T, Fukushima E, Suzutani $\mathrm{T}$ (2007) Tolerance of loop-mediated isothermal amplification to a culture medium and biological substances. J. Biochem. Biophys Methods 70, 499-501.

17. Yano A, Ishimaru R, Hujikata R (2007) Rapid and sensitive detection of heat-labile I and heat-stable I enterotoxin genes of enterotoxigenic Escherichia coli by Loop-Mediated Isothermal Amplification. $J$ Microbiol Methods 68, 414-20.

18. Ahmad F, Stedtfeld RD, Waseem H, Williams MR, Cupples AM, Tiedje JM, Hashsham SA (2017) Most probable number-loop-mediated isothermal amplification (MPN-LAMP) for quantifying waterborne pathogens in $<25 \mathrm{~min}$. $J$ Microbiol Methods 132, 2733.

19. Tanaka N, Iwade Y, Yamazaki W, Gondaira F, Varaporn Vuddhakul YN, Nishibuchi M (2014) Most-probablenumber loop-mediated isothermal amplificationbased procedure enhanced with $\mathrm{K}$ antigen-specific immunomagnetic separation for quantifying $t d h^{\text {? }}$ $V$. parahaemolyticus in molluscan shellfish. $J$ Food Prot 77, 1078-85.

20. Carnevale ML, Roche PJR, Najih M, Paliouras M, Beitel LK, Trifiro MA (2015) A rapid diagnostic method for $E$. coli serogroups responsible for gastro-intestinal diseases using loop-mediated isothermal amplification. Anal Methods 7, 287-95.

21. Goularte L, Martins CG, Morales-Aizpurúa IC, Destro MT, Franco BDGM, Vizeu DM, Hutzler BW, Landgraf M (2004) Combination of minimal processing and irradiation to improve the microbiological safety of lettuce (Lactuca sativa, L.). Radiat Phys Chem 71, 157-61.

22. APHA (2012) Microbiological examination. In: Eugene WR, Laura B (eds) Standard Methods for the Examination of Water and Wastewater, 22nd edn, American Public Health Associaton, Washington, DC.

23. Feng P, Weagant S, Grant M, Burkhardt W (2002) BAM4: enumeration of Escherichia coli and the Coliform Bacteria. In: Bacteriological Analytical Manual, U.S. Food and Drug Administration, Silver Spring, MD.

24. Kongrueng J, Tansila N, Mitraparp-arthorn P, Nishibuchi M, Vora GJ, Vuddhakul V (2015) LAMP assay to detect $V$. parahaemolyticus causing acute hepatopancreatic necrosis disease in shrimp. Aquacult Int 23, 1179-88.

25. Yamazaki $\mathrm{W}$, Ishibashi $\mathrm{M}$, Kawahara $\mathrm{R}$, Inoue $\mathrm{K}$ (2008) Development of a loop-mediated isothermal amplification assay for sensitive and rapid detection of V. parahaemolyticus. BMC Microbiol 8.

26. Wang F, Yang Q, Qu Y, Meng J, Ge B (2014) Evaluation of a loop-mediated isothermal amplification suite for the rapid, reliable, and robust detection of Shiga toxin-producing Escherichia coli in produce. Appl Environ Microbiol 80, 2516-25.

27. Yang W, Song X, Wang J, Li Z, Ji M, Li Y (2014) Detection methods for milk pathogenic bacteria by loopmediated isothermal amplification. Biosci Trends 8, 316-21.

28. Ferenc J, Oliver J, Witkowski R, McLandsborough L, Levin RE (2000) Studies on the Growth of Escherichia coli 0157:H7 Strains at $45.5^{\circ} \mathrm{C}$. J Food Prot 63, 1173 8. 